\title{
FATORES CONDICIONANTES DA QUALIDADE E DA VARIAÇÃO DO NÍVEL DAS ÁGUAS SUBTERRÂNEAS NO MUNICÍPIO DE MERUOCA, CEARÁ
}

\section{CONDITIONING FACTORS IN THE QUALITY AND LEVEL VARIATION OF GROUNDWATER IN MERUOCA MUNICIPALITY, CEARÁ (BRASIL)}

\author{
Mickaelon Belchior Vasconcelos, Carla Maria Salgado Vidal Silva, José Antônio Beltrão Sabadia, \\ José Geraldo de Melo e Marlúcia Freitas Santiago
}

\begin{abstract}
RESUMO É apresentado neste trabalho uma descrição da infraestrutura hídrica do Município de Meruoca e uma discussão acerca dos fatores que interferem na qualidade e quantidade das águas subterrâneas. A área é composta de quatro unidades geológicas, as quais apresentam diferentes condicionantes quanto ao armazenamento de águas subterrâneas, conforme a seguir: Manto de alteração e Rochas cristalinas fraturadas, que favorecem o armazenamento de água; Rochas cristalinas com ausência relativa de fraturamentos e Rochas vulcânicas, cuja estrutura não permite o armazenamento de água. A captação de água é feita nas seguintes condições: $87 \%$ são poços escavados, $9 \%$ são poços tubulares e 4\% são fontes naturais. Foram monitorados os níveis de água de 9 poços escavados durante 3 anos, com a obtenção de uma variação de carga hidráulica de $1 \mathrm{~m}$ até $6 \mathrm{~m}$. Verificou-se que estes poços reagem rapidamente após a ocorrência das chuvas, atestando assim as condições de um aqǘfero livre. Foram realizadas 18 análises químicas de compostos da série nitrogenada $\left(\mathrm{NH}_{4}{ }^{+}, \mathrm{NO}_{2}{ }^{-}\right.$e $\left.\mathrm{NO}_{3}{ }^{-}\right)$, e 9 análises físico-químicas completas (incluindo os cátions e ânions principais) em poços escavados e tubulares distribuídos pelo município. As águas são bicarbonatadas sódicas e cloretadas sódicas. Os cátions são, provavelmente, originados das rochas predominantes na área, que são rochas graníticas com feldspatos sódicos e cálcicos. A ocorrência dos ânions dominantes pode ser associada à velocidade do fluxo das águas, à evaporação, ou possível contribuição antropogênica. As águas são em geral de boa potabilidade.
\end{abstract}

Palavras-chave: Rochas Cristalinas, Qualidade das águas, Poços escavados, Variação sazonal, Ceará

\begin{abstract}
This work describes the Meruoca's water supply and discusses the factors that have influenced the quantity and quality of groundwater. Four hydrogeological situations in the area were considered: alteration mantle and fractured crystalline rocks, whose structure is good to storage water; no fractured crystalline rocks, represented by granites and volcanic rocks, that aren't good to storage water. The Meruoca's groundwater supply is achieved mainly by dug wells (87\%), followed tube wells (9\%) and natural sources (4\%). Dug wells water levels were monitored during 3 years and was verified that the water table changes from $1.0 \mathrm{~m}$ up to $6,0 \mathrm{~m}$. Was observed that the water level in the dug wells has immediate response during the rain, attesting the condition of an unconfined aquifer. Nine samples were collected to complete chemical analysis and eighteen (18) samples to partial analyses, including the nitrogenous series compounds $\left(\mathrm{NH}_{4}, \mathrm{NO}_{2}\right.$ e $\left.\mathrm{NO}_{3}\right)$. The chemical results indicated $\mathrm{Na}-\mathrm{HCO}_{3}$ and $\mathrm{Na}-\mathrm{Cl}$ water type. The quality of water is good to human supply, in most of the cases.
\end{abstract}

Keywords: Crystalline Rocks, Groundwater Quality, dug wells, seasonal variations, Ceará state

\section{INTRODUÇÃO}

O município de Meruoca (Figura 1), com aproximadamente $150 \mathrm{~km}^{2}$, e população de 10.000 hab., está inserido no contexto de rochas cristalinas, apresentando uma característica bastante peculiar que é a sua elevada altitude, que atinge aproximadamente $800 \mathrm{~m}$ em pleno semiárido, o que proporciona, localmente, a formação de um microclima diferenciado no estado do Ceará. Meruoca destaca-se por apresentar a geomorfologia dos Maciços Residuais (SOUZA, 1988) e pela sua pluviosidade média próxima dos $1.600 \mathrm{~mm}$, enquanto $75 \%$ do Estado estão inseridos na isoieta abaixo dos $800 \mathrm{~mm}$ anuais (FUNCEME, 1991). Informa-se que no Nordeste Brasileiro, a produção média de poços no cristalino, com profundidade média de $40 \mathrm{~m}$, é da ordem de $3 \mathrm{~m}^{3} / \mathrm{h}$. A salinidade das águas é elevada, com sólidos totais dissolvidos da ordem de 3.000 mg/L (MANUEL FILHO, 1996).

Neste trabalho são feitas considerações sobre o suprimento hídrico do Município de Meruoca, avaliado a qualidade das águas subterrâneas e as flutuações de nível da água nos poços com a ocorrência das chuvas.

\section{Infra-estrutura do sistema hídrico de abastecimento}

O sistema de abastecimento hídrico do município de Meruoca é composto de 245 pontos de água (Figura 1), constituídos de poços escavados $(87 \%)$, poços tubulares $(9 \%)$ e fontes naturais (4\%), de acordo com o cadastro de poços realizado por Vasconcelos et al., (2003), o que mostra a importância da água subterrânea para o abastecimento da população local. 


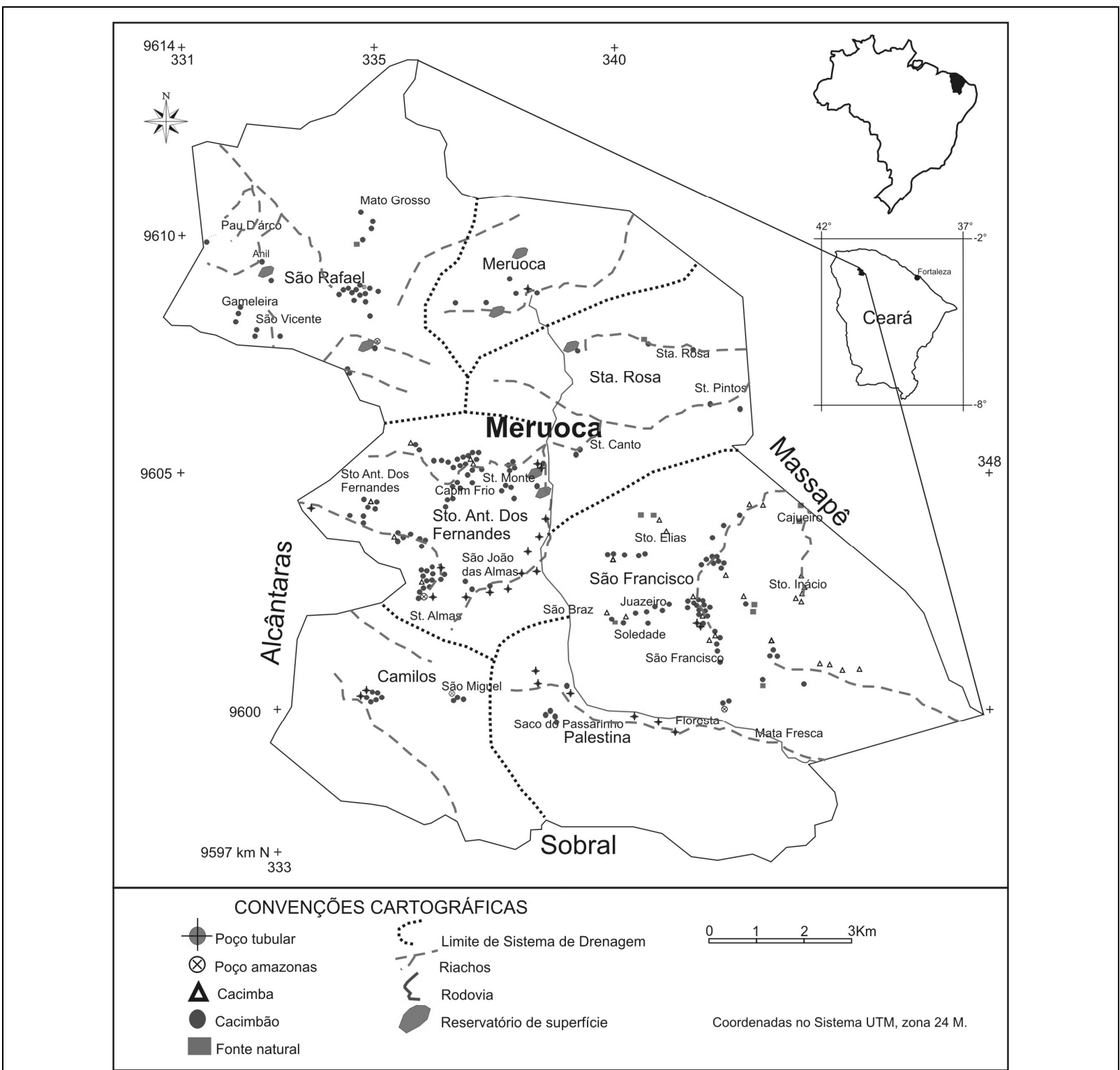

Figura 1 - Localização da área de estudo com pontos de água cadastrados.

Figure 1 - Study area localization and the distribution of the water points.

Dos poços escavados, do tipo cacimbão, $54 \%$ captam água usando motor elétrico e $41 \%$ captam água de forma rudimentar (manualmente) e $5 \%$ possui captação mista. Os reservatórios superficiais no município pouco contribuem para o abastecimento, com exceção do açude Flexeiras que abastece parte da Sede do Município. O município de Meruoca foi dividido em sete sistemas de drenagem, de acordo com as subbacias hidrográficas (Tabela 1). O sistema de drenagem São Francisco é o que possui maior número de pontos de água com $35 \%$, seguido do Santo Antonio dos Fernandes com 34\%, São Rafael com $13 \%$, Palestina com 6\%, Camilos com $6 \%$, Santa Rosa com 4\% e Meruoca com $3 \%$.

Os poços tipo cacimbão predominam no município devido à facilidade de execução e baixo custo em relação a um poço tubular. Os poços do tipo cacimba (poço sem revestimento) possuem menor representatividade no abastecimento, mas algumas localidades, nos sistemas de drenagem São Francisco (26 poços) e Santo Antônio dos Fernandes (6 poços) são abastecidas por este tipo de captação. Na figura 2 é apresentado o perfil construtivo de um poço tubular e de um poço amazonas construídos no sistema de drenagem Palestina, os quais são utilizados para abastecimento da comunidade local.

\section{UNIDADES GEOLÓGICAS E CONDIÇÕES PARA O ARMAZENAMENTO DE ÁGUA}

Foi realizado um mapeamento geológico para a identificação das áreas relativamente favoráveis à ocorrência de águas subterrâneas. 
Tabela 1 - Pontos de água do município de Meruoca distribuídos por sistemas de drenagem.

Table 1 - Meruoca Municipality water points through drainage

\begin{tabular}{|c|c|c|c|c|c|c|}
\hline \multirow{2}{*}{$\begin{array}{l}\text { Sistema de } \\
\text { Drenagem }\end{array}$} & \multicolumn{3}{|c|}{ Poço Escavado } & \multirow{2}{*}{$\begin{array}{c}\text { Poço } \\
\text { Tubular }\end{array}$} & \multirow{2}{*}{$\begin{array}{c}\text { Fonte } \\
\text { Natural }\end{array}$} & \multirow[b]{2}{*}{ Total } \\
\hline & $\begin{array}{c}\text { Cacimbão } \\
(\emptyset<5 \mathrm{~m})\end{array}$ & $\begin{array}{c}\text { Cacimba } \\
\text { (sem revestimento) }\end{array}$ & $\begin{array}{l}\text { Amazonas } \\
(\emptyset \geq \mathbf{5} \mathrm{m})\end{array}$ & & & \\
\hline Camilos & 09 & - & 01 & 02 & - & 12 \\
\hline Meruoca & 06 & - & - & 01 & - & 07 \\
\hline Palestina & 07 & - & 01 & 06 & - & 14 \\
\hline Santa Rosa & 07 & 01 & - & - & - & 09 \\
\hline São Francisco & 52 & 26 & - & 01 & 08 & 87 \\
\hline $\begin{array}{l}\text { Santo Antonio } \\
\text { dos Fernandes }\end{array}$ & 63 & 06 & 01 & 13 & - & 83 \\
\hline São Rafael & 30 & - & 02 & - & 01 & 33 \\
\hline Total & $\begin{array}{c}174 \\
(71 \%)\end{array}$ & $\begin{array}{c}33 \\
(14 \%)\end{array}$ & $\begin{array}{c}05 \\
(2 \%)\end{array}$ & $\begin{array}{c}23 \\
(9 \%)\end{array}$ & $\begin{array}{c}09 \\
(4 \%)\end{array}$ & $245(100 \%)$ \\
\hline
\end{tabular}

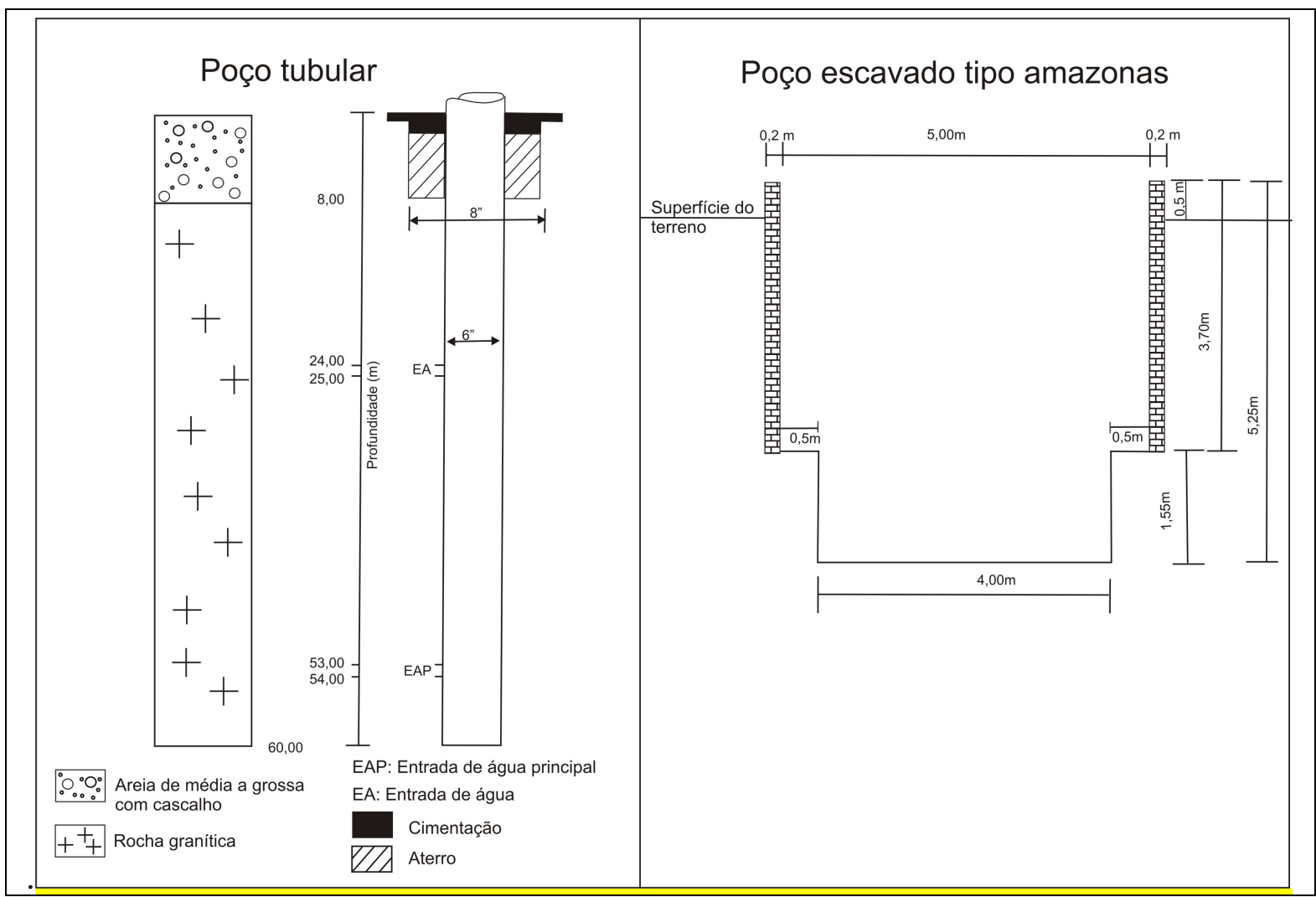

Figura 2 - Perfil construtivo e litológico de poços da área de estudo.

Figure 2 - Constructive and lithologic wells profiles of the study area.

Tal mapeamento foi elaborado com base em imagens de satélite Landsat TM- 5 (ano de 1992) e Landsat ETM-7 (ano de 2000) e atividades de campo. Os resultados indicaram a ocorrência de quatro unidades hidrogeológicas, considerando a capacidade relativa de armazenamento de águas subterrâneas (Figura 3) e conforme indicadas a seguir.

- Mantos de alteração com cobertura de sedimentos alúvio-coluviais

- Rochas cristalinas fraturadas

- Rochas vulcânicas
- Rochas cristalinas com ausência relativa de fraturas (graníticas)

\section{MANTOS DE ALTERAÇÃO COM COBERTURA DE SEDIMENTOS ALÚVIO- COLUVIAIS}

Correspondem a mantos de intemperismo localizados nos fundos dos vales, cobertos com uma camada de espessura mal definida ou variável de sedimentos aluvionares e coluviais, estes não superiores a um metro. 


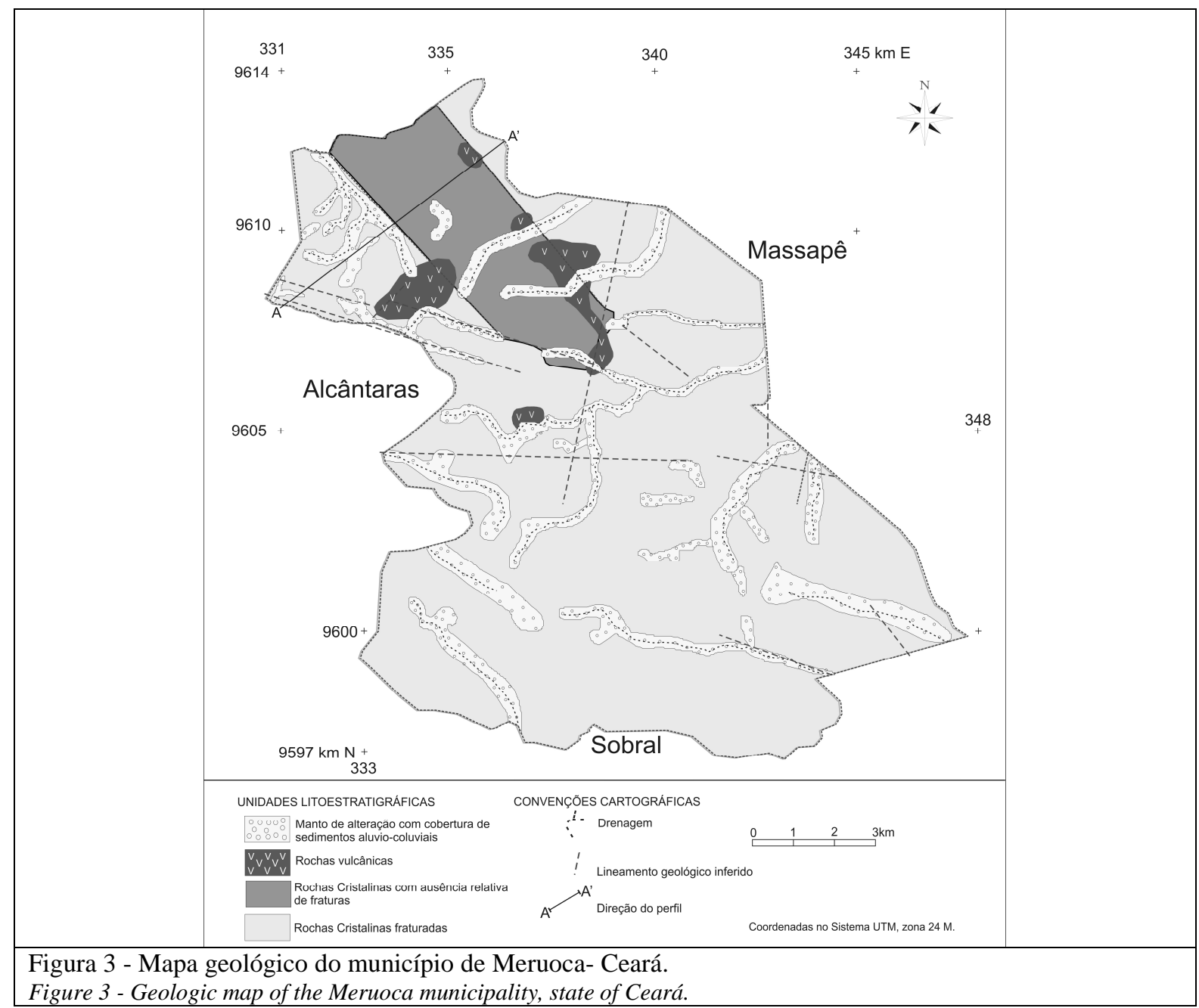

São encontrados em todos os sistemas de Drenagem e dentre as unidades hidrogeológicas são as mais utilizadas no abastecimento do município, pois os poços escavados captam água desta unidade. Compreendem aproximadamente 19\% da área do Município, apresentando coloração variável, com tonalidades branca a vermelha.

A espessura média do manto de alteração nos vales é de aproximadamente $8 \mathrm{~m}$, com uma maior freqüência de poços escavados com profundidade média de $4 \mathrm{~m}$. Nas áreas em que os processos erosivos estão mais atuantes, o manto de alteração está mais próximo da superfície ou mesmo aflorando.

\section{ROCHAS VULCÂNICAS}

Estes litotipos são representados por diabásios, que ocorrem na forma de blocos em diversas áreas do município, associados e controlados por fraturamentos. Como corpo armazenador de água subterrânea, esta unidade geológica não é muito favorável, em decorrência da ausência de fraturamentos.

\section{ROCHAS CRISTALINAS}

As rochas cristalinas englobam um grupo de rochas metamórficas e ígneas, as quais constituem um aqǘf́ero fissural. $\mathrm{O}$ processo de recarga ocorre nas zonas de fraqueza das rochas, se processando com mais intensidade nos domínios de fraturas abertas e com boa interconexão hidráulica entre as mesmas. Apresenta um comportamento hidráulico variável que depende de fatores associados com a tectônica regional e pelo tipo de minerais presentes na rede cristalina da rocha.

$\mathrm{Na}$ área de estudo foram identificados dois tipos básicos de unidades aqüíferas fissurais: Rochas Cristalinas fraturadas e Rochas Cristalinas pouco fraturadas.

Para análise da distribuição dos fraturamentos que ocorrem na área de estudo, foram realizadas interpretações das imagens de satélite que permitiram extrair os lineamentos geológicos e correlacioná-los com as informações do campo.

A análise dos lineamentos, bem como do fraturamento, foi semelhante à feita por 
Albuquerque et al. (2003) com a geração de três mapas:

1- Lineamentos, extraídos a partir da interpretação das imagens Landsat 5.

2- Lineamentos, extraídos a partir da rede de drenagem.

3- Fraturamentos, obtidos com informações de campo.

No âmbito deste trabalho são apresentados somente os resultados referentes aos aspectos geológicos e estruturais, associando às informações características das unidades descritas como susceptíveis ao armazenamento de água.

\section{Rochas cristalinas fraturadas}

Verificou-se a existência de diferentes direções de fraturamentos, muitos deles preenchidos com material com textura mais fina, provavelmente decorrente das pulsações do pluton durante sua fase de esfriamento. a ausência de um número satisfatório de perfis de poços dificulta a interpretação da profundidade de ocorrência dos fraturamentos. as informações de profundidade (penetratividade) e mergulho das fraturas são escassas, sendo restritas a poucos afloramentos.

Estas rochas estão melhores condicionadas ao armazenamento de água no fundo dos vales, pois recebem lentamente, as águas do manto de alteração, o qual torna-se, neste caso, um meio facilitador da recarga das águas subterrâneas do meio fraturado.

O perfil geológico da área, com base em dados de altitudes relativas a informações de radar do SRTM (2003) está apresentado na figura 4. A direção do mergulho dos planos de falhas não foi possível ser inserida em decorrência da ausência de afloramentos. A espessura da cobertura aluvial é inexpressível na escala apresentada; nos falhamentos inferidos na porção SW, não sendo identificado, em campo nenhuma diferença na litologia.

As rochas cristalinas fraturadas são representadas basicamente por um granito de coloração avermelhada que possui variações no tamanho dos cristais, mas predominando os grossos, apresentando cristais com diâmetro superior a $0,5 \mathrm{~cm}$.

\section{Rochas cristalinas com ausência relativa de fraturas}

Esta unidade está delimitada por duas fraturas de direção noroeste, localizadas na porção centro norte do município. Neste grupo de rochas estão aqueles litotipos que apresentam relativamente menor número de fraturas, com ocorrência em uma área relativamente pequena, sendo representada por granitos de coloração cinza e verde.

\section{FLUXO DAS ÁGUAS SUBTERRÂNEAS}

O fluxo das águas subterrâneas, segundo as propriedades hidrogeológicas de cada unidade aqüífera, ocorre de duas maneiras:

a) Nos sedimentos alúvio-coluviais e no manto de alteração, representantes dos meios intergranulares dos sedimentos inconsolidados possuem fluxo limitado nas laterais e em profundidade pelo corpo granítico, que por sua vez faz com que as águas escoem na mesma direção do escoamento superficial.

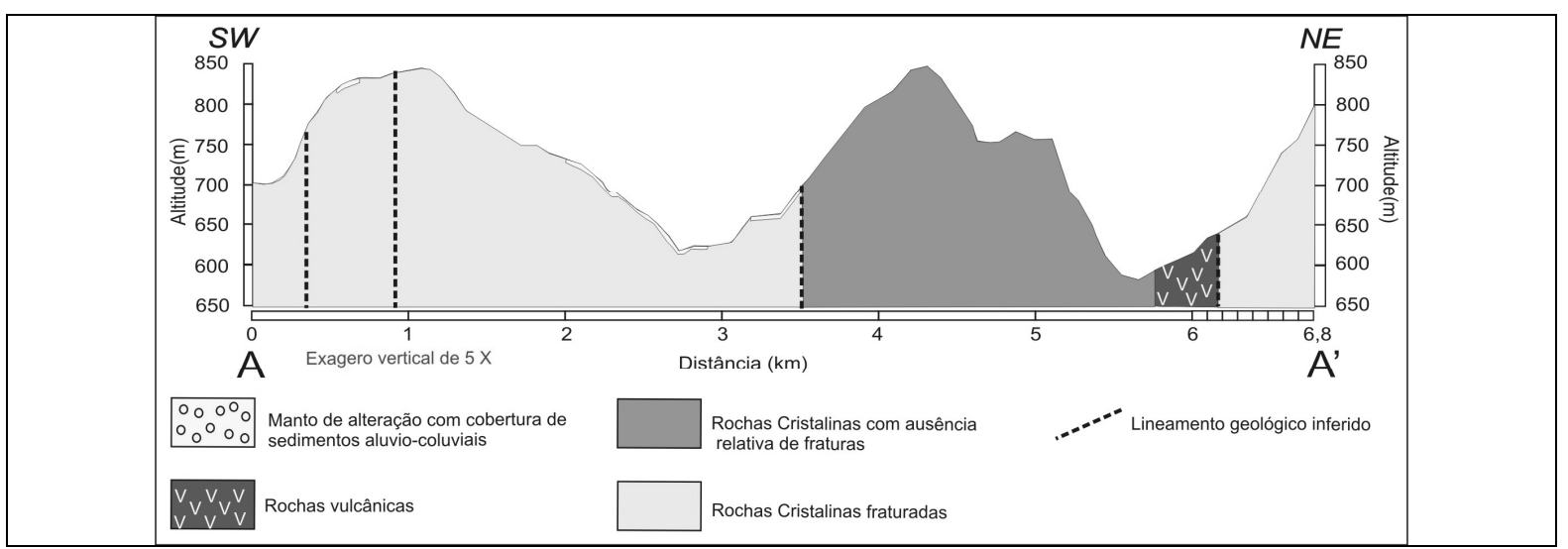

Figura 4 - Perfil geológico esquemático A-A' na porção NW do município de Meruoca.

Figure 4 - Schematic cross section A-A” in the Meruoca Municipality NW portion. 
A velocidade e a direção do fluxo nesta unidade aqüífera podem variar em decorrência da presença de lentes de argilas. No município, ocorrem diferentes direções de fluxo subterrâneo em decorrência das várias redes de drenagens independentes. $\mathrm{O}$ fluxo em macroescala das águas subterrâneas está concordante com o escoamento de superfície.

b) Nas rochas cristalinas, um meio anisotrópico, o fluxo não possui direção preferencial, tendo como maior condicionante a presença de fraturamento e características do mesmo como: abertura, material de preenchimento e rugosidade.

\section{VARIAÇÃO SAZONAL DO NÍVEL ESTÁTICO EM POÇOS ESCAVADOS}

Foram monitorados 09 poços escavados em uma parte do sistema de drenagem São Francisco nos períodos secos e chuvosos com intuito de se detalhar a dinâmica de recarga das águas subterrâneas no aquífero do manto de alteração.
Como estes poços são construídos de forma artesanal, os mesmos não apresentam informações construtivas ou litológicas. Os poços monitorados estão inseridos no manto de alteração com um pequeno capeamento de sedimentos alúvio-coluviais.

As características e a localização dos poços escavados são apresentados na tabela 2 e Figura 5. Os poços estão localizados em uma microbacia hidrográfica de aproximadamente $1,6 \mathrm{~km}^{2}$, dentro do sistema de drenagem São Francisco, onde predomina um relevo montanhoso com uma variação altimétrica de aproximadamente $150 \mathrm{~m}$. Os poços monitorados possuem utilização para uso doméstico de pequenas famílias, e as medidas de nível estático foram obtidas quando os mesmos se encontravam a um tempo satisfatório sem possuir interferências decorrente do bombeamento.

O poço que apresentou uma maior variação do nível estático foi o Co35, este encontra-se no setor sul da bacia, apresentando uma variação de $\mathrm{NE}$ de $6,00 \mathrm{~m}$, e o poço que apresentou uma menor variação de NE foi o Co39, com 1,10 m.

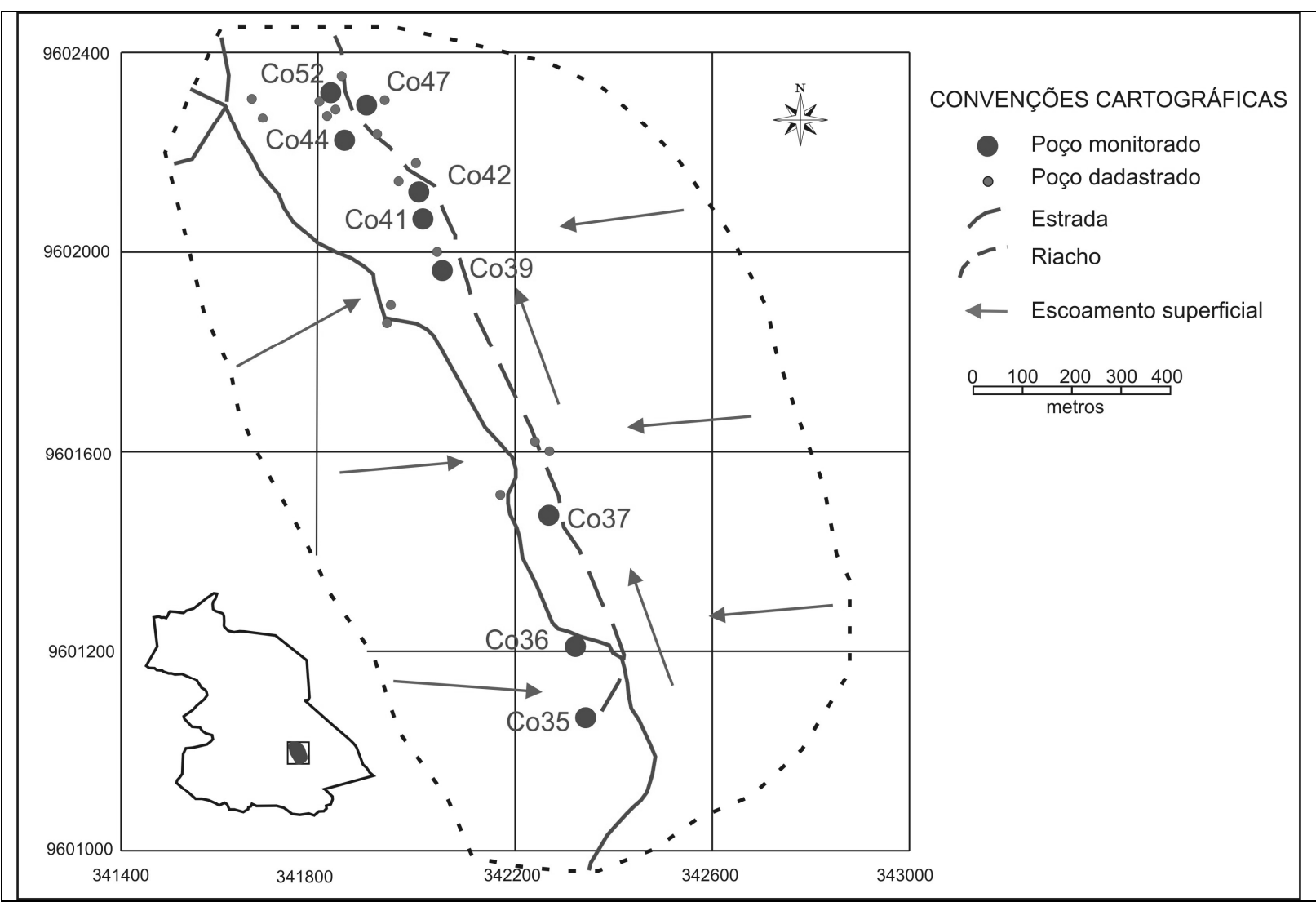

Figura 5 - Localização dos poços monitorados do sistema São Francisco, município de Meruoca.

Figure 5 - Spatial distribution of the Monitoring wells in the São Francisco drainage system, Meruoca Municipality 
Tabela 2 - Características e resultados da variação do nível estático dos poços escavados monitorados do sistema de drenagem São Francisco, município de Meruoca,CE.

Table 2 - Results and characteristics of the static level variation monitoring of dug wells in the São Francisco drainage system, Meruoca Municipality, $C E$

\begin{tabular}{c|c|c|c|c|c|c|c}
\hline RG & \multicolumn{2}{c|}{$\begin{array}{c}\text { Coordenadas } \\
\text { UTM }\end{array}$} & $\begin{array}{c}\text { Diâmetro } \\
(\mathbf{m})\end{array}$ & $\begin{array}{c}\text { Boca } \\
(\mathbf{m})\end{array}$ & $\begin{array}{c}\text { Profundidade } \\
(\mathbf{m})\end{array}$ & $\begin{array}{c}\text { Variação } \\
\text { do NE (m) }\end{array}$ & $\begin{array}{c}\text { Tipo de } \\
\text { Revestimento }\end{array}$ \\
\hline $\mathbf{C o 3 5}$ & 9601025 & 342350 & 2,2 & 0,6 & 11,1 & 6,00 & Pedra \\
\hline $\mathbf{C o 3 6}$ & 9601249 & 342305 & 3,4 & 0,4 & 4,9 & 1,32 & Tijolo \\
\hline $\mathbf{C o 3 7}$ & 9601547 & 342293 & 2,4 & 0,6 & 3,9 & 3,91 & Tijolo \\
\hline Co39 & 9601989 & 342048 & 2,5 & 0,5 & 5,1 & 1,10 & Tijolo \\
\hline Co41 & 9602077 & 342015 & 2,2 & 0,5 & 4,5 & 1,39 & Tijolo \\
\hline Co42 & 9602133 & 341992 & 2,2 & 0,5 & 4,4 & 1,30 & Tijolo \\
\hline Co44 & 9602210 & 341892 & 3,0 & 0,5 & 6,1 & 2,12 & Tijolo \\
\hline Co47 & 9602274 & 341897 & 2,8 & 0,9 & 6,5 & 2,32 & Tijolo \\
\hline Co52 & 9602281 & 341812 & 2,7 & 0,4 & 5,0 & 2,33 & Tijolo \\
\hline
\end{tabular}
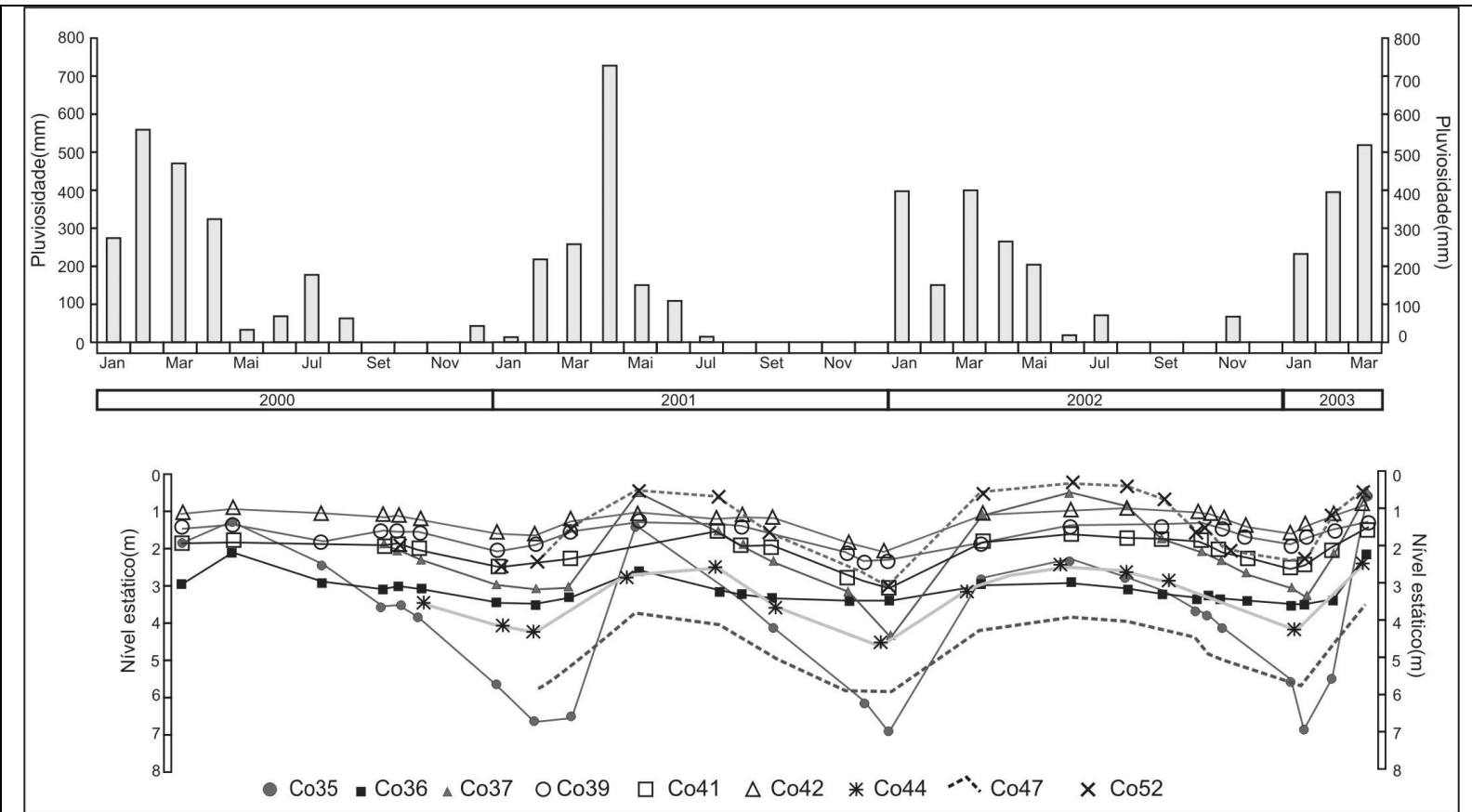

Figura 6 - Nível estático dos poços, correlacionados com a pluviosidade registrada no período de monitoramento.

Figure 6 - Wells Static level and its correlation to the pluvial precipitation during the monitoring period.

Observa-se na figura 6 que o poço localizado na extremidade sul (Co35), possui uma maior variação de $\mathrm{NE}$, no entanto não existe uma correlação direta entre essa variação e a posição dos poços no sub-sistema de drenagem, pois o poço Co36 apresentou uma variação de NE menor do que outros poços localizados no norte da bacia hidrográfica, a jusante. Este comportamento sugere a existência de pelo menos dois sistemas hidrogeológicos dentro do sub-sistema de drenagem que foi monitorado. Estas diferenças no comportamento dos poços podem ser geradas por variações da profundidade 
das rochas cristalinas e consequentemente na espessura do manto de alteração.

\section{QUALIDADE DAS ÁGUAS SUBTERRÂNEAS}

Foram coletadas nove amostras de água subterrânea nos locais indicados na figura 8 para análises físico-químicas (Tabela 3) completas e 18 amostras para análises de nitrato, nitrito e amônia. A coleta das amostras foi realizada em setembro de 2004 (período seco) (Figura 8). Os resultados das análises químicas estão apresentados no diagrama de Piper, representado pela figura 7 .

Das nove amostras analisadas, oito são do tipo cloretada sódica, e apenas a amostra F-2 é bicarbonatada sódica (Figura 7), O cloreto é provavelmente originado das precipitações pluviométricas que carreiam este íon da atmosfera. O íon sódio é originado principalmente da intemperização dos minerais.

Tabela 3 - Resultados das análises físico-químicas.

Table 3 - The physical - chemical analyses results of the water samples collected from the wells.

\begin{tabular}{|c|c|c|c|c|c|c|c|c|c|c|c|c|}
\hline \multirow[b]{2}{*}{ Ponto } & \multicolumn{10}{|c|}{ Concentração (mg/L) } & \multirow{2}{*}{$\frac{C E}{(\mu \mathrm{S} / \mathrm{cm})}$} & \multirow[t]{2}{*}{ pH } \\
\hline & $\mathrm{Ca}^{2+}$ & $\mathbf{M g}^{2+}$ & $\mathrm{Na}^{+}$ & $\mathbf{K}^{+}$ & $\mathrm{Fe}^{2+}$ & $\mathbf{A l}^{3+}$ & $\mathrm{Cl}^{-}$ & $\mathrm{SO}_{4}{ }^{2-}$ & $\mathrm{HCO}_{3}{ }^{-}$ & STD & & \\
\hline F-1 & 6,0 & 2,2 & 19,1 & 3,4 & 1,76 & 0,03 & 21,7 & 11,1 & 39,0 & 108 & 132 & 5,9 \\
\hline F-2 & 16,8 & 8,8 & 38,7 & 1,8 & 0,23 & 0,01 & 10,8 & 8,8 & 147,5 & 257 & 281 & 7,3 \\
\hline F-3 & 9,6 & 14,1 & 42,0 & 1,3 & 0,08 & 0,01 & 40,4 & 6,3 & 116,9 & 233 & 301 & 6,5 \\
\hline F-4 & 4,0 & 3,4 & 15,3 & 5,2 & 0,05 & 0,03 & 13,8 & 8,9 & 27,8 & 79 & 106 & 5,7 \\
\hline F-5 & 6,8 & 5,6 & 29,1 & 10,4 & 0,01 & 0,02 & 40,4 & 13,9 & 41,7 & 151 & 237 & 5,8 \\
\hline F-6 & 6,4 & 1,9 & 20,1 & 3,9 & 0,04 & 0,08 & 24,1 & 8,9 & 27,8 & 96 & 146 & 6,5 \\
\hline F-7 & 4,8 & 3,9 & 39,8 & 10,4 & 0,09 & 0,50 & 55,2 & 18,7 & 11,1 & 148 & 273 & 4,9 \\
\hline F-8 & 8,4 & 5,1 & 23,5 & 5,2 & 0,02 & 0,02 & 33,0 & 3,2 & 29,2 & 138 & 211 & 5,9 \\
\hline F-9 & 5,2 & 1,2 & 12,6 & 5,2 & 0,01 & 0,04 & 12,8 & 6,0 & 36,2 & 84 & 112 & 6,0 \\
\hline
\end{tabular}

CE: Condutividade elétrica; $\mathrm{pH}$ : potencial hidrogeniônico; STD: sólidos totais dissolvidos.

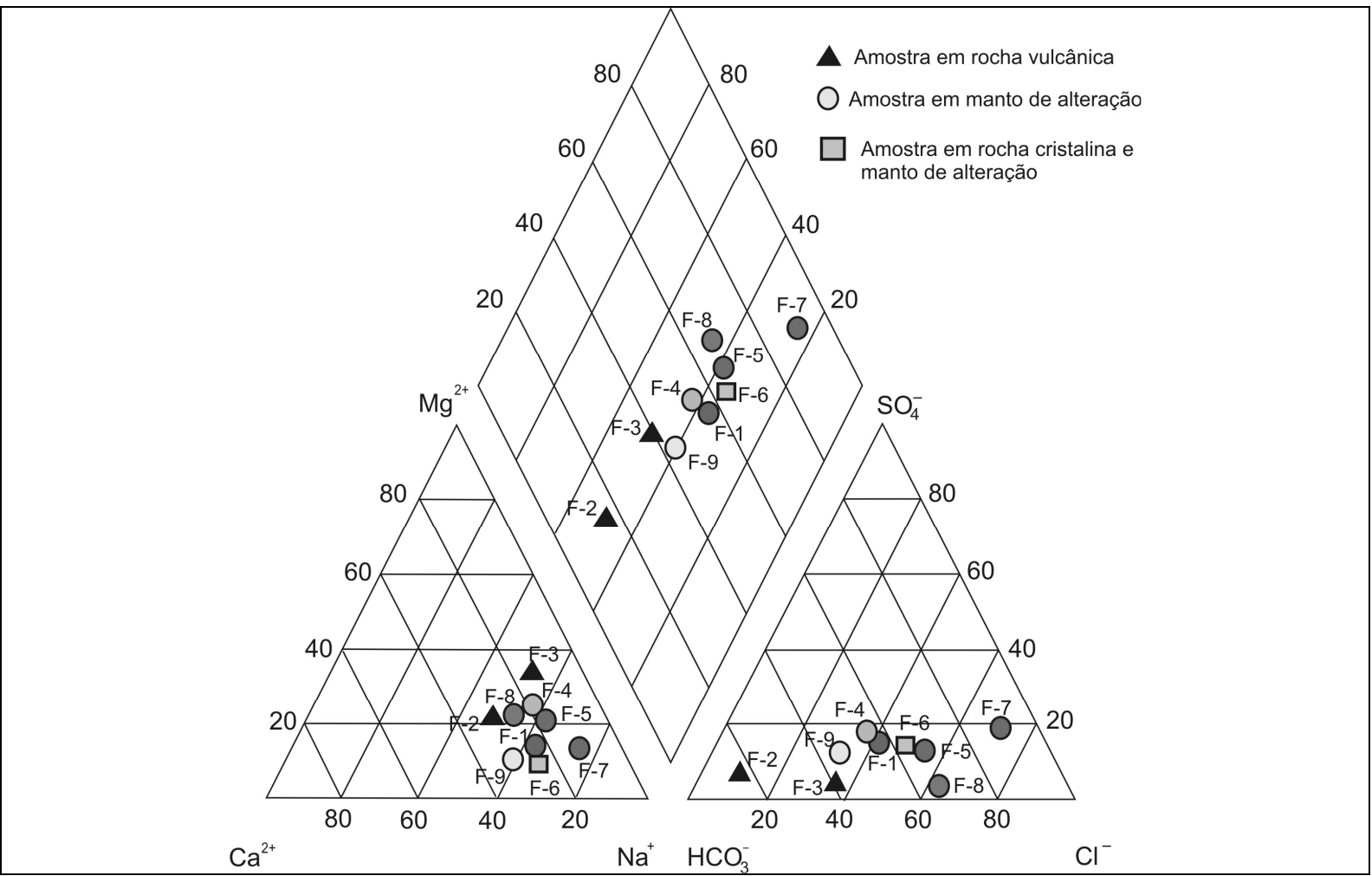

Figura 7 - Diagrama de Piper das amostras de água coletadas na área de estudo Figure 7 - Piper's Diagrams of groundwater samples collected in the study area. 


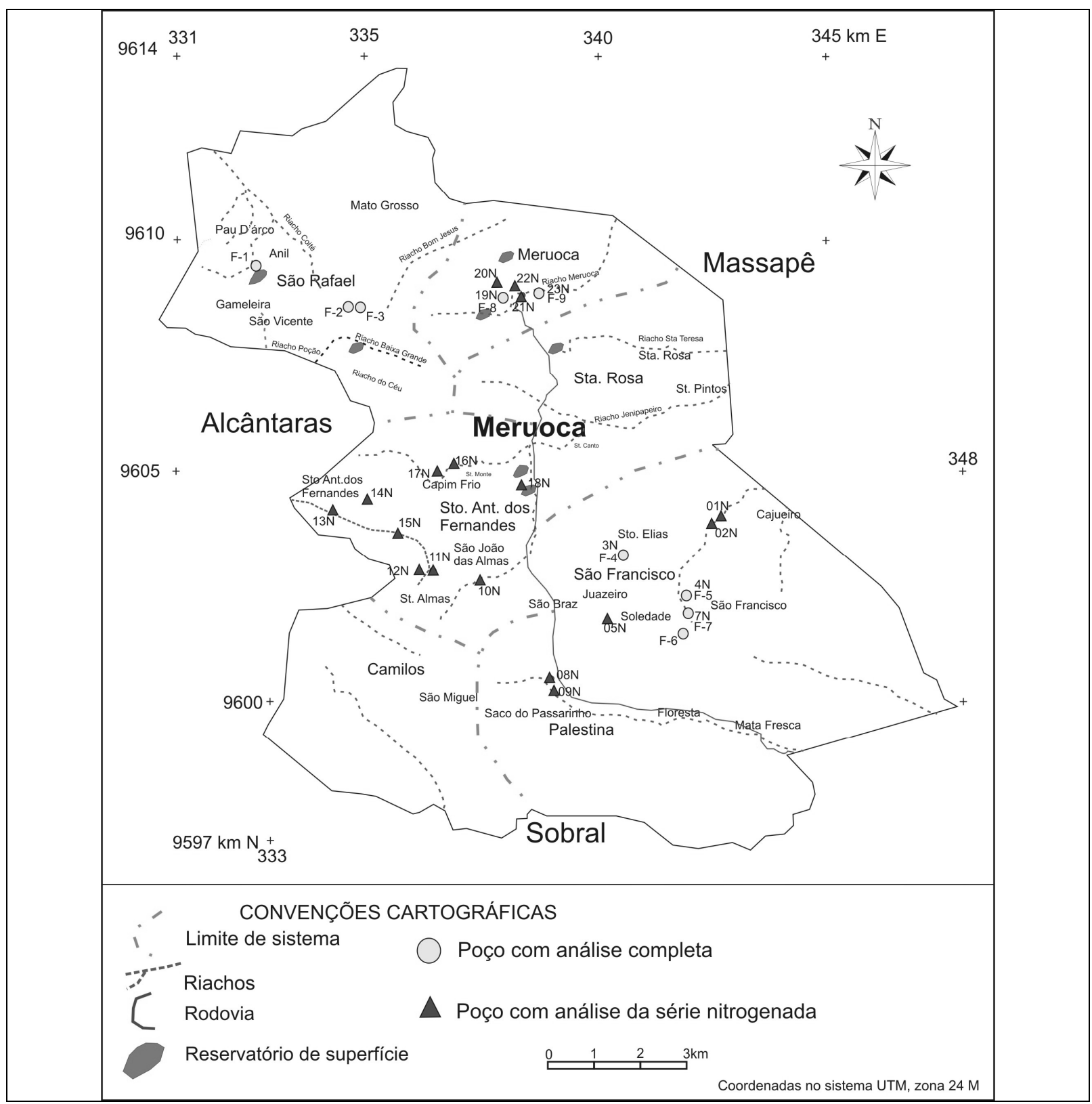

Figura 8 - Distribuição dos locais de coleta das amostras de água.

Figure 8 - The distribution of the waters sampling points in the Meruoca municipality.

A amostra F-2 é bicarbonatada sódica provavelmente em decorrência das rochas vulcânicas que nesta área ocorrem em subsuperfície. Nesta amostra, o segundo sal predominante é o bicarbonato de cálcio, mostrando assim, uma possível influência dos feldspatos (plagioclásios cálcicos) das rochas vulcânicas.

A amostra F-6, coletada em um poço tubular, tem qualidade química de água semelhante à dos poços escavados indicando, neste caso, que não houve diferença da qualidade das águas quanto ao tipo de aquíffero explotado (Tabela 4).

Nas águas com análise dos elementos nitrogenados (Tabela 3 ), a condutividade elétrica variou de $85 \mu \mathrm{S} / \mathrm{cm}$ a $620 \mu \mathrm{S} / \mathrm{cm}$ e o pH de ácido $(4,9)$ a neutro $(7,3)$. A amostra F-7 se destaca por apresentar valor de sulfato superior ao das demais amostras, com 18,7 mg/L (Tabela 3), enquanto a média nas outras amostras é de $9,5 \mathrm{mg} / \mathrm{L}$. Este ín tem origem biogênica, visto que as rochas predominantes na área são granitos que não contêm este elemento. 
Tabela 4 - Tipo de água, tipo de poço e unidade geológica captada.1: cloretada sódica e 2: bicarbonatada sódica.

Table 4 - Water type, well type and geologic unit 1: $\mathrm{Na}$-Cl and 2: $\mathrm{Na}-\mathrm{HCO}_{3}$

\begin{tabular}{c|c|c|c}
\hline Amostra & $\begin{array}{c}\text { Tipo da } \\
\text { água }\end{array}$ & Tipo de poço & Unidade geológica \\
\hline F-1 & 1 & escavado & Mando de alteração \\
\hline F-2 & 2 & escavado & Manto de alteração/ Rochas vulcânicas \\
\hline F-3 & 1 & escavado & Manto de alteração/ Rochas vulcânicas \\
\hline F-4 & 1 & escavado & Manto de alteração \\
\hline F-5 & 1 & escavado & Manto de alteração \\
\hline F-6 & 1 & tubular & Manto de alteração/ Rochas cristalinas \\
\hline F-7 & 1 & escavado & Manto de alteração \\
\hline F-8 & 1 & escavado & Manto de alteração \\
\hline F-9 & 1 & escavado & Manto de alteração \\
\hline
\end{tabular}

O diagrama de Piper (Figura 7) indica, em relação aos cátions, que as amostras são sódicas e em relação aos ânions são cloretadas, mistas ou bicarbonatadas, com a maior diferença entre as amostras F-7 e F-2. Os mais elevados valores de $\mathrm{Ca}^{2+}$ foram encontrados nos poços F-2 e F-3 localizados no domínio das rochas vulcânicas.

\section{Série nitrogenada: Nitrito, nitrato e amônia}

O conhecimento dos compostos nitrogenados é útil para verificar indícios de contaminação por compostos orgânicos como fezes animais ou humanas, bem como decomposição de matéria orgânica. Como a maior parte das captações é realizada através de poços escavados que são vulneráveis à contaminação, buscou-se analisar a qualidade química da água através dos compostos nitrogenados. Esta série permite estudar o processo de nitrificação que envolve a transformação do nitrogênio amoniacal $\left(\mathrm{NH}_{3}\right.$, $\mathrm{NH}_{4}{ }^{+}$) em nitrato através de duas reações sob a ação de bactérias amonificadoras (ESTEVES, 1998):

Pela ação de bactérias autótrofas dos gêneros Nitrosomonas e Nitrosococcus, a amônia se transforma em nitrito.

$$
\begin{gathered}
\mathrm{NH}_{4}^{+}+1 / 2 \mathrm{O}_{2} \rightarrow \mathrm{NO}_{2}^{-}+2 \mathrm{H}^{+}+\mathrm{H}_{2} \mathrm{O} \\
\mathrm{NO}_{2}^{-}+1 / 2 \mathrm{O}_{2}^{-} \rightarrow \mathrm{NO}_{3}^{-}
\end{gathered}
$$

Pela ação de bactérias dos gêneros Nitrobacter e Nitrococcus o nitrito se transforma em nitrato.

Os limites permitidos de potabilidade pelo Ministério da Saúde (BRASIL, 2004) nas concentrações dos compostos nitrogenados para que as águas são: $\mathrm{NH}_{4}{ }^{+}=1,5 \mathrm{mg} / \mathrm{L}, \mathrm{NO}_{2}{ }^{-}=1,0$ $\mathrm{mg} / \mathrm{L}$ e $\mathrm{NO}_{3-}-\mathrm{N}^{-}=10 \mathrm{mg} / \mathrm{L}$.
$\mathrm{O} \mathrm{pH}$ da água determina o equilíbrio entre o $\mathrm{NH}_{4}$ e o amoníaco $\mathrm{NH}_{3}$, se o $\mathrm{pH}$ diminui ocorre uma reação que produz $\mathrm{NH}_{4}$, caso contrário ocorre a produção de $\mathrm{NH}_{3}$ (FENZL, 1986). Na série dos compostos nitrogenados existe também o processo de transformação de nitrato em amônia $\left(\mathrm{NH}_{3}\right)$ ou gás nitrogênio $\left(\mathrm{N}_{2}\right)$. Este processo ocorre em solos que apresentam muito calcário, em solos encharcados deficientes em aeração e com baixo grau de oxigenação (CARVALHO, 1995). A contaminação por compostos nitrogenados ocorreu somente no poço $10 \mathrm{~N}$ que apresentou concentração de nitrato de $15,4 \mathrm{mg} / \mathrm{L}$, acima do limite permitido (10 mg/L), ou seja, na maioria dos casos as águas explotadas não estão contaminadas ou afetadas por contaminantes nitrogenados.

Tabela 5 - Resultados das análises da série nitrogenada.

Table 5 - The results of the nitrogen series analysis.

\begin{tabular}{c|c|c|c|c|c}
\hline Amostra & \multicolumn{3}{|c}{$\begin{array}{c}\text { Concentração } \\
\text { (mg/L) }\end{array}$} & $\mathbf{p H}$ & $\mathbf{C E}$ \\
\hline & $\mathrm{NH}_{4}{ }^{-}$ & $\mathrm{NO}_{3}{ }^{-}$ & $\mathrm{NO}_{2}{ }^{-}$ & & $(\mu \mathrm{S} / \mathrm{cm})$ \\
\hline $\mathbf{1 N}$ & 0,3 & 2,41 & 0,06 & 6,0 & 187 \\
\hline $\mathbf{2 N}$ & 0,1 & 0,0 & 0,03 & 5,5 & 91 \\
\hline $\mathbf{3 N} / \mathbf{F} 4$ & 0,0 & 0,0 & 0,04 & 5,7 & 106 \\
\hline $\mathbf{4 N} / \mathbf{F 5}$ & 0,2 & 0,20 & 0,03 & 5,8 & 237 \\
\hline $\mathbf{5 N}$ & 0,5 & 0,0 & 0,03 & 6,0 & 521 \\
\hline $\mathbf{6 N}$ & 0,7 & 0,0 & 0,03 & 5,6 & 252 \\
\hline $\mathbf{7 N} / \mathbf{F} 7$ & 0,2 & 0,0 & 0,02 & 4,9 & 273 \\
\hline $\mathbf{8 N}$ & 0,4 & 2,62 & 0,03 & 5,9 & 393 \\
\hline $\mathbf{9 N}$ & 0,4 & 2,30 & 0,03 & 5,7 & 389 \\
\hline $\mathbf{1 0 N}$ & 0,4 & 15,40 & 0,07 & 5,1 & 620 \\
\hline $\mathbf{1 1 N}$ & 0,5 & 4,76 & 0,03 & 5,2 & 412 \\
\hline $\mathbf{1 2 N}$ & 0,6 & 1,46 & 0,05 & 5,9 & 184 \\
\hline $\mathbf{1 3 N}$ & 0,6 & 0,11 & 0,04 & 6,2 & 189 \\
\hline $\mathbf{1 4 N}$ & 0,6 & 2,93 & 0,07 & 6,0 & 136 \\
\hline $\mathbf{1 5 N}$ & 0,6 & 0,0 & 0,04 & 5,5 & 85 \\
\hline $\mathbf{1 6 N}$ & 1,2 & 0,4 & 0,04 & 6,3 & 268 \\
\hline $\mathbf{1 7 N}$ & 1,5 & 1,03 & 0,05 & 6,2 & 226 \\
\hline $\mathbf{1 8 N}$ & 0,8 & 0,51 & 0,04 & 5,7 & 171 \\
\hline
\end{tabular}




\section{CONCLUSÕES}

O município de Meruoca depende das águas subterrâneas para o desenvolvimento e sustentação das populações locais. A estrutura geológica das rochas cristalinas não é favorável para o armazenamento de água, sendo o manto de alteração a unidade aqüífera mais representativa para o armazenamento e captação de água.

A variação do nível da água nos poços escavados está diretamente relacionada às chuvas, possuindo os mesmos uma rápida recarga.

As águas subterrâneas no município de Meruoca são de boa qualidade para o uso humano. $\mathrm{O}$ aqüífero explotado (manto de alteração) mostra-se como a unidade mais vulnerável à contaminação, visto que possuem uma rápida recarga.

Os fatores geológicos e estruturais são os principais elementos que afetam a salinidade das águas. Os cátions dominantes nas águas estão associados diretamente ao tipo de rocha predominante na área, que são rochas graníticas com feldspatos sódicos e cálcicos, enquanto que a ocorrência dos ânions dominantes pode ser associada à velocidade do fluxo das águas, a evaporação, bem como devido a uma possível contribuição antropogênica. 


\section{REFERÊNCIAS}

ALBUQUERQUE, A.P.B; MELLO, C.L.; PIZANI, T.C.; SILVA JUNIOR, G.C.; Análise do Fraturamento Neotectônico Aplicada a Avaliação Hidrogeológicada Bacia Sedimentar de Resende (RJ), I Simpósio de Hidrogeologia do Sudeste, 2003.

BRASIL, Ministério da Saúde, Portaria n ${ }^{\circ} \mathbf{5 1 8}$ de 25 de março de 2004- Estabelece os procedimentos e responsabilidades relativos ao controle e vigilância da qualidade da água para consumo humano e seu padrão de potabilidade, e dá outras providências, 2004.

CARVAlHO, I.G.; Fundamentos da Geoquímica dos Processos Exógenos, Bureau Gráfica e Editora Ltda, Salvador, Bahia, 239 p. 1995.

ESTEVES, F.A.; Fundamentos de Limnologia. Ed. Interciência, 1998.

FENZL,N; Introdução a Hidrogeoquímica, UFPA, 189p. 1986.

FUNCEME; Análise preliminar do valor mais provável da medida de tendência central das séries anuais de precipitação no Ceará, Fundação Cearense de Meteorologia e Recursos Hídricos,1991.
LARSSON,I; Groundwater in hard rocks, International Seminar, Stockholm-Cagliari, Sweden, 1977.

MANOEL FILHO, J.; Modelo de Dimensão Fractal para Avaliação de Parâmetros Hidráulicos em Meio Fissural. Tese de Doutorado, Instituto de Geociências, USP, 197 p, 1996.

SOUZA, M.J.N. Contribuição ao Estudo das Unidades Morfo-Estruturais do Estado do Ceará in: Revista de Geologia vol. 1, 1988.

SRTM, Shuttle Radar Topography Mission (SRTM) Courtesy NASA/JPL-Caltech, 2003.

VASCONCELOS, M.B; SILVA, C.M.S.V; SANTIAGO, M.M.F.; SABADIA, J.A.B; Caracterização do Sistema de Abastecimento Hídrico do Município de Meruoca-CE In: XV Simpósio Brasileiro de Recursos Hídricos, 2003.

VASCONCELOS, M.B; SILVA, C.M.S.V; SABADIA, J.A.B; LIMA, J.O.G. MELO, J.G. SANTIAGO, M.M.F.; Geologia e Qualidade das Águas no Município de Meruoca, Ceará. In Congresso Latino Americano de Hidrologia Subterrânea, 2006. 